\section{UNIVERSIDAD NACIONAL DE TUMBES VICERRECTORADO DE INVESTIGACIÓN INSTITUTO DE INVESTIGACIÓN}

\section{MANGLAR}

Revista de investigación Científica

ISSN 1816-7677

Título Clave: Manglar (Tumbes, Perú)

Título Clave abreviado: Manglar (Tumbes, Perú)

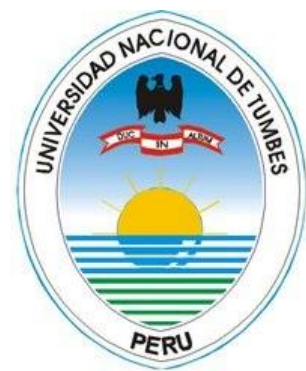

Julio - Diciembre, 2015 Volumen 12, Número 2

\title{
Comité Editor
}

\section{Presidente:}

Dr. Gerardo Juan Francisco Cruz Cerrro

\section{Miembros:}

MSc. Luis Jhony Caucha Morales

Dr. Ramón Garcia Seminario

MSc. Cesar Estuardo Poma Sanchez

Dra. Maritza Purizaga Sorroza

Lic. Balgelica Antazara Cervantes Rujel

Abog. Raul Chiroque Guerrero

\section{Editor Científico:}

Dr. Victor Ricardo Alvitres Castillo

Producción Editorial:

MSc. Jorge Fupuy Chung

\section{Autoridades Universitarias}

Rector

Vicerrector de Investigación

Vicerrector Académico
: Dr. Carlos Alberto Canepa La Cotera

: Dr. Manuel Ernesto Paz Lopez

: Dr. Elber Lino Moran Coronado

\section{Edición y Publicación:}

Dirección de Gestión, Innovación y Transferencia Tecnológica

E-mail: revistamanglar@untumbes.edu.pe

Impreso en:

Universidad Nacional de Tumbes - diciembre 2015 


\section{MANGLAR \\ Revista de investigación Científica de la Universidad Nacional de Tumbes, Perú \\ ISSN 1816-7677}

Volumen 12, Número 2

Julio - Diciembre 2015

\section{CONTENIDO}

\section{Editorial}

\section{Artículos originales}

Efecto del fotoperiodo y temperatura sobre la maduración y reproducción de Cynoscion phoxocephalus ("Ccorvina-Ccherela") en la zona norte del Perú

Effect of photoperiod and temperature in the maturation and reproduction of Cynoscion phoxocephalus (Ccorvina-Cherela) in the north of Peru

Edissa Palacios, Yovani Rosales, Geoffrey Rabinovich

Dietas con ensilado biológico de restos del procesamiento de langostino (Litopenaeus vannamei) con inoculo de microrganismos benéficos del tracto digestivo de lechones (Sus escrofa domestica) Tumbes, Perú, 2014 - 2015

Diets with biological silage of remains of the prawn prosecution (Litopenaeus vannamei) with inoculate of beneficent microrganismos of the digestive tract of the piglet in the feeding of piglets (Sus escrofa domestica) Tumbes, Peru, 2014 - 2015 Héctor Sánchez S., Gloria Ochoa M.

Influencia de Eichhornia crassipes y microorganismos eficientes sobre contaminantes químicos y orgánicos de las aguas residuales de Naranjito, Ecuador Influence of Eichhornia crassipes and efficient microorganisms on chemical and organic pollutants of the wastewater of Naranjito, Ecuador

Freddy Gavilánez Luna

Influencia de un abono orgánico líquido tipo biol en el rendimiento de la lechuga (Lactuca sativa L) cultivada en sistemas hidropónicos

Influence of a liquid organic fertilizer type biol on the yield of lettuce (Lactuca sativa L) grown in hydroponic systems

Sucre Cando Pacheco, Leocadio Malca Acuña

Predicción temprana de preeclampsia con doppler de las arterias uterinas y resultados materno perinatales; Hospital Regional II-2 de Tumbes, Perú

Early prediction of preeclampsia with uterine artery Doppler and perinatal maternal outcomes; Regional hospital

Amarilis Calle, Grevillí García, Feliciano Gutarra, Magalli Ramos, Lyzeth Gutarra

Apuntes y propuestas sobre la democratización de la sociedad peruana

Some notes and proposals on the democratization of Peruvian society Carlos León D

Uso del Smartphone en estudiantes de $2^{\text {o }}$ año Escuela Administración de Empresas de universidad particular de Chiclayo

Use of the Smartphone in students of 2nd year School of Business Administration of the private university of Chiclayo

Cristian Loconi C., Víctor Alvitres C., Beatriz Ortega P., Irune Zapirain N. 


\section{Editorial}

\section{La Universidad en la gestión y difusión de producción del conocimiento}

La Universidad es, en el campo de las ciencias, tecnologías, las humanidades y las artes, gene radora y difusora del conocimiento científico, tecnológico y humanístico, y es en este contexto que está comprometida con la protección del medio ambiente y el desarrollo sostenible del país; que se conexa con la formación de los profesionales, pues para esta Casa Superior de Estudio, el conocimiento es la materia esencial y a la vez el producto, relevante en la gestión: la planificación, su ejecución y valoración de los resultados.

Para la planificación, la universidad asume la investigación como una de las tareas primordiales, que se establece desde la Constitución Política del Perú, pasando con preeminencia por la Ley Universitaria 30220 (siendo uno de los principios, fines y funciones) y el Estatuto de cada Universidad. Para la gestión de ejecución de las investigaciones es esencial el financiamiento, por lo que la gestión debe realizarse con fondos del estado, el apoyo de la empresa y entidades financiadoras del conocimiento. En tanto que para valoración de la producción del nuevo conocimiento al servicio de la comunidad es esencial la divulgación, básicamente a través de las revistas científicas.

La revista Manglar de la Universidad Nacional de Tumbes es uno de los principales canales para impulsar la difusión científica de esta institución académica y es clave para mejorar e incrementar la formación, la cultura y los conocimientos científicos de los ciudadanos y de significancia para el desarrollo social y económico de las comunidades, por eso se insta a los investigadores de la región y del país a contribuir con sus investigaciones de calidad; asimismo, se constituye para potenciar la participación de la comunidad científica y el intercambio de información, conocimiento y experiencias.

En este número de la Revista Manglar (vol 12, num 2, 2105) se presenta diferentes temas de interés nacional e inter nacional, aportes significativos para el desarrollo y la investigación en las diferentes áreas del conocimiento. En las ciencias marinas se presenta el experimento para un acercamiento al conocimiento de la fisiología reproductiva de Cynoscion phoxocephalus ("corvina -cherela"), evaluando el efecto de la temperatura y fotoperiodo en la reproducción. En el área de veterinaria se presenta un experimento DCA con 4 tratamientos y 3 repeticiones de dietas, con ensilado biológico de restos del procesamiento de langostino (Litopenaeus vannamei) con inoculo de microrganismos benéficos del tracto digestivo de lechones (Sus escrofa domestica) a fin de mejorar su valor nutritivo, digestibilidad, y utilizarlo como un insumo alternativo para la alimentación lechones de destete. En las ciencias médicas se expone el estudio descriptivo sobre predicción temprana de preeclampsia con doppler, de las arterias uterinas y resultados materno perinatales.

En investigaciones internacionales en ciencias agrarias se presenta un experimento DCA, con 4 tratamientos para determinar la influencia de Eichhornia crassipes y microorganismos eficientes sobre contaminantes químicos y orgánicos de una planta de tratamiento de agua residual; asimismo se presenta otro experimento DCA con 4 tratamientos, para determinar la influencia de un abono orgánico líquido tipo biol sobre el rendimiento de la lechuga (Lactuca sativa) cultivada en sistemas hidropónicos.

También con invitados de otras universidades, se describe propuestas para la democratización de la sociedad peruana, y la investigación uso del Smartphone en estudiantes de $2^{\circ}$ año de una Escuela de Administración de Empresas de universidad particular.

La Universidad Nacional de Tumbes aspira a convertirse en un sistema de unidades operativas de investigación, enseñanza superior y creación de cultura científica y humanística, necesaria para incorporar la ciencia al conocimiento integral de la ciudadanía y mejorar la visibilidad de la investigación a nivel nacional e internacional.

Víctor Alvitres $C$. Editor revista Manglar 
